\title{
International Journal of English and Literature
}

\section{Full Length Research Paper}

\section{Semantic roles in Ruluuli-Runyala}

\begin{abstract}
Atuhairwe Amos
Department of African Languages, School of Languages, Literature and Communication Skills, Makerere University, Uganda.
\end{abstract}

Received 13 February, 2020; Accepted 23 March, 2020

\begin{abstract}
In this paper, we provide a detailed analysis of the semantic roles of applicative arguments in RuluuliRunyala. We present the semantic roles of applicative objects in view of the participant roles as semantically defined under sense relations: There is a general assumption that arguments of a verb could be allocated only one of these roles. The analysis follows the theoretical framework which contextualises participant roles in respect of the meanings of sentences, and often less in terms of grammatical position of referring expressions in sentences. We show the participant roles as indicators of relationships between a verb (and possibly other predicators) and the referring expressions in a sentence. Notably, we identify beneficiary, location, goal, instrument, patient, possessum and temporal participant roles in Ruluuli-Runyala. We show similarities and parametric variations between RuluuliRunyala and other languages in literature. We conclude that although Ruluuli-Runyala is to a larger extent semantically unspecified in assigning semantic roles to applicative arguments as in most Bantu languages, it has examples of semantically specified applicative use.
\end{abstract}

Key words: Semantic roles, grammar, applicative objects, double applicatives, lexicalised cases.

\section{INTRODUCTION}

The objective of this paper is to examine the sematic roles of applicative arguments in Ruluuli-Runyala. We capture various sense relation notions that are descriptive of the semantic roles of an applicative object in Ruluuli-Runyala.

Ruluuli-Runyala is a tonal Bantu language of the NigerCongo language family spoken by some of the inhabitants of River Nile-Lake Kyoga basin of Central Uganda. Ruluuli-Runyala is labelled JE.103, under group E10 of Nyoro-Ganda in Maho (2009)'s classification system. According to Nakayiza (2013), four districts of Luweero, Masindi, Nakasongola and Kayunga have
Ruluuli-Runyala speakers. However, this study found that Ruluuli-Runyala is also spoken in the adjoining Lake Kyoga districts of Buyende, Amolatar and Kiryandongo. Eberhard et al.(2019) mention that there are roughly 237,699 speakers of Ruluuli-Runyala in Uganda.

Different terms for 'participant roles' have been used in literature, for instance, semantic roles(Hurford et al., 2007; Reimer, 2016), theta-roles (Knyazev, 2018), thematic relations (Davis, 2011; Valin, 1999) as well as deep semantic cases (Givón, 1990). According to Marten and Mous (2015), applicative objects which are morphologically marked are associated with semantic

E-mail: atuhairweamos@yahoo.com.

Author(s) agree that this article remain permanently open access under the terms of the Creative Commons Attribution License 4.0 International License 
qualities. We adopted the term semantic roles in this study because it was more commonly used by most scholars in the recent semantic literature that we reviewed (Hurford et al., 2007; Reimer, 2010, 2016; Saeed, 2016). The semantic roles of a word combine with a set of coarse complementation patterns to form what is called behavioural profile. Such behaviour makes the semantic roles of applied object vary according to the meaning of the base (Dixon, 2009). As a consequence, several semantic roles can be assigned to applicative objects (Kimenyi, 1995; Woolford, 2001; Ngoboka, 2005). Although Pacchiarotti (2017:60) noted that the applicative can introduce numerous "peripheral" semantic roles of the morphosyntactic entity, she pointed out that such characterisation does not explain fully applicative constructions across Bantu languages.

\section{METHODOLOGY}

We used corpus and participant observation methods of data collection since grammatical analyses should be arrived at inductively, through observations of a corpus of recorded discourse, supplemented by direct observation of how the language is used in the community (Dixon, 2012). One needs to gather a broad database which should contain numerous genres, and thereafter supplementary data should be gathered through participant observation which is under elicitation methodology (Bowern, 2015).

We used Ruluuli-Runyala-English Dictionary (RRED) corpus data which was compiled by a Ruluuli-Runyala language documentation project: A comprehensive bilingual talking Ruruuli/Runyala-English dictionary with a descriptive basic grammar for language revitalisation and enhancement of mother-tongue based education (PI SaudahNamyalo, Makerere University, funded for 2017-2020, Volkswagen Foundation). The RRED corpus consisted of 159,641 words from 74 written Ruluuli-Runyala texts. The corpus was produced by speakers of Ruluuli-Runyala from four districts of Uganda, namely Nakasogola, Kayunga, Kiryandongo and Buyende.

\section{RESULTS AND DISCUSSION}

\section{Semantic roles of applicative objects}

\section{Beneficiary applicative object}

Beneficiary is considered the most widespread and productive of all semantic roles of applicatives in Bantu languages (Schadeberg, 2003). According to De Kind and Bostoen (2012), it is the most frequently and most typically associated with applied objects. The general notion embedded in the term 'beneficiary' implies that an action can either be negatively of positively affected depending on the nature of the action. Thus, it also encompasses the notion of maleficiary. In RuluuliRunyala, beneficiary is used to refer to the semantic role of bene/malefactive (Woolford, 2001; Van de velde, 2010) as illustrated in sentences (1a) and (1b) below:

(1) Ruluuli-Runyala (Bantu, Uganda; Primary source) (a) A-ku-sumb-ir-a ba-geni ki-nage

3sgS-PROG-cook -APPL-FV 2-guests

7-fish

'He is cooking fish for the guests.'

(b) E-biduuma bi-tandik-ire oku-n-kal-i-ir-a

AUG-7.maize 7S-start-PFV INF-1sgO-

get_dry-APPL-APPL-FV

'The maize is getting dry to my disadvantage.'

In sentence (1a) above, the benefactive object bageni 'visitors' is positively affected with respect to the action of the verb sumbira 'cook for'. In contrast, the malefactive object $1 \mathrm{sgO}$ ' $\mathrm{me}$ ' is negatively affected in respect of the action of the verb kaliira'dry to one's disadvantage' in sentence (1b). Similar to Tswana, the double applicative i-ir- appears to function as a single applicative by adding a maleficiary to the construction and acquiring a lexicalised meaning (Pacchiarotti, 2017). In a situation of a single applicative kal+ir 'dry+APPL' can only form an applicative with a locative phrase as shown below:

(c) E-biduuma bi-kal-ir-a omu musiri. AUG-8.maize 8S-dry-APPL-FV 18.LOC3.garden 'Maize dry from the garden.'

There are other verbs by which their use of the double applicative brings about a lexicalised meaning of the verb similar to (1b) above. In contrast, the use of a single applicative licenses a locative phrase as in sentence (1c) above. The other verbs in the same category are given in Table 1.

Table 1 indicates how certain verbs carry a malefactive reading when used with double applicatives but restricted to locative phrases in instances of single applicatives. The lexicalised malefactives can be interpreted as follows: kal-i-ir-a 'dry to one's disadvantage', sal-i-ir-a 'pain to one's annoyance', mal-i-ir-a 'finish up something to one's disadvantage', babil-i-ir-a 'irritate (of body part) to one's discomfort'.

\section{Locative applicative object}

Locative applicative is an applicative construction in which an original locative argument is placed in a transitive object position (Dixon, 2012:493). This is deduced from the role of the applicative argument when occurring in peripheral function marker in the original non-applicative construction. Constructions involving to, from, along, towards, into, in, on and others combine with verbs to enable locative applicative derivation in English interpretation. We analysed semantic features of locative arguments based on transitive, intransitive and typological syntactic structures as found in relevant literature. A plain intransitive construction of locative applicatives is illustrated in the sentence below:

(2)Ruluuli-Runyala (Bantu, Uganda; Primary source) 
Table 1. Double applicatives in Malefactives vs single applicatives in locative phrases.

\begin{tabular}{lllll}
\hline Basic verb & Locative phrase (LP) & $\begin{array}{l}\text { Locative phrase } \\
\text { (single applicative) }\end{array}$ & $\begin{array}{l}\text { Malefactive } \\
\text { (Lexicalised) }\end{array}$ & $\begin{array}{l}\text { Malefactive } \\
\text { (double applicative) }\end{array}$ \\
\hline Kala 'dry' & Kaara 'dry at/in' & kal+APPL+LP & kal-i-ir-a & kal+APPL+APPL \\
Sala 'pain' & Saara 'pain at/in' & sal+APP+LP & sal-i-ir-a & sal+APPL+APPL \\
Mala 'finish' & Maara'finish at/in' & mal+APPL+LP & mal-i-ir-a & mal+APPL+APPL \\
Babila 'irritate' & Babiira 'irritate at/in' & babil+APPL+LP & babil-i-ir-a & babil+APPL+APPL \\
\hline
\end{tabular}

Source: Primary source.

1sgS-PST-run-PFV

'I ran.'

(b) $\mathrm{N}$-a-iruk-i-ire e Lango.

1SgS-PST-run-APPL-PFV 17.LOC 1.Lango

'I ran to/in/from Lango.'

In Ruluuli-Runyala, an intransitive verb iruka 'run' cannot take a peripheral argument without applicativisation. The sentence is not marked by any preposition in the nonapplicative construction of the intransitive sentence (2a). However, the introduction of a locative argument in sentence (2b) necessitates an applicative verb. It is the applicative marker that enables the locative NP e Lango 'to/in/from Lango' to take the transitive object function. Sentence $(2 b)$ can have three pragmatic interpretations: It means either 'he' ran to Lango as in to flee for safety or 'he' ran in Lango to mean his running took place in Lango, possibly in a running competition. It can also mean'he fled from lango.' In regard to the three interpretations, 'to' is regarded as an allative preposition, 'in' is locative, while 'from' is considered an ablative preposition because iruka 'run' is a verb of motion (Beck, 2009; Dixon, 2009;Jerro, 2017). In Ruluuli-Runyala, locative applicative derivations can also occur with transitive verbs as exemplified below:
(3) Ruluuli-Runyala (Bantu, Uganda; Primary source) $\mathrm{N}$-a-zaal-i-ire-ku a-baana omu i-lwariro

1sgS-PST-produce-APPL-PFV-ECL AUG-2.child 18.LOC 5.hospital

'I produced some children in the hospital.'

In the Example 3 above, the only way the locative argument omuilwariro 'in the hospital' can assume a transitive object function is through applicativisation. Different scholars (Dixon, 2012;Jerro, 2017; Rugemalira, 1993) have through their works shown that locative applicatives need not be generalised. Some verb meanings in objects that can be assigned the semantic role of locative could be language specific and carry unique pragmatic interpretations. The typological analysis of Jerro (2017:4) on Runyarwanda locative applicatives gives four meanings that may be construed from applicative verbs - Locative, Path, Goal and Source.
Jerro takes the typology of motion to involve a complete motion event in which an agent moves from a SOURCE, along a PATH and ends at a GOAL. We consider this typology of locative arguments and then comment on each in respect of Ruluuli-Runyala for which data is analogous but not entirely identical. We point out that these locative meaning categories do not encompass all locative interpretations as depicted in Ruluuli-Runyala.

We start with the general LOCATIVE role that indicates where the event took place. The action expressed by the applicative verb occurs with a local adposition in a language such as English (Dixon, 2009). This is normally enabled by a locative preposition in, on, at, up, around and others.

(4) Ruluuli-Runyala (Bantu, Uganda; Primary source)

(a) O-buntu obwo bu-landa

AUG-14.plant_type 14.REL 14S-creep

'That plant type creeps.'

(b) O-buntu obwo bu-land-ir-a okumuyembe. AUG-14.plant_type 14.REL 14S-creep-APPL-FV 17.LOC 3.mango

'That plant type creeps up the mango tree.'

The intransitive verb landa 'creep' in sentence (4a) gives a complete meaning but can take a locative argument in the periphery function. As a result, the introduction of a locative applied object okumuyembe 'upthe mango tree' necessitates an applicative construction as shown in sentence (4b). Pacchiarotti (2017:20) refers to such locative applied objects as 'optional locative prepositional phrases'. Contrary to Jerro's use of locative prefixes $k u$ and $m u$ as class markers, oku 'up' as used in sentence $(4 b)$ is a preposition. The general locative meaning can also be expressed in double applicative construction as given in the sentence below:

(5) Ruluuli-Runyala (Bantu, Uganda; Primary source)

(a) Ya-zub-ire ku e-izuba

A-a-zub-PFV 17.LOC AUG-5.well

'He weeded around the well.'

(b) Ya-zub-i-ir-ire izuba.

A-a-zub-APPL-APPL-PFV

'He weeded around the well.' 
According to sentence (5a), general locative meaning can be expressed with the locative marker ku 'around' in nonapplicative construction. The double applicative construction in sentence (5b) equally represents the place where the event, in this case, 'weeding' took place. The second category locative meaning Jerro (2017) gives is a GOAL to the event that a verb describes. The action expressed by the verb is directed towards the locative goal represented by the applied object. According to Cann and Mabugu (2007:232), the applied object should ideally be interpreted as 'real locative goal'. They go on to call it the 'true goal'. De Kind and Bostoen (2012:10) define the applied object as 'the participant to whom the action expressed by the verb is directed'. Such an expression of direction involves verbs of transfer like tuma 'send', of speech like koba 'say' and intransitive verbs of movement like yaba 'go' (De Kind andBostoen, 2012). In addition to iruka 'run' and yaba 'go', there are other specific verbs that can be attributed to the locative GOAL meaning as pitirya 'go about' and guluka 'jump' (Jerro, 2017). Interestingly, none of the given examples can analogously indicate a locative GOAL meaning in Ruluuli-Runyala. Since we have already considered the verb iruka 'run' under sentence (4), we use different examples below:

(6) Ruluuli-Runyala (Bantu, Uganda; Primary source)

(a) A-ku-guluk-a 3sgS-PROG-jump-FV

'He is jumping.'

(b) A-ku-guluk-ir-a omu lubuga

3sgS-PROG-jump-APPL-FV 18.LOC 11.compound 'He is jumping in the compound.'

The verb guluka 'jump' can be used either intransitively as in sentence (6) above or with an obligatory applicative argument. There is no other semantic role beyond that of general locative that can be assigned to such a construction.

The absence of a locative GOAL is also illustrated below using the verb yaba 'go'. Sentence (7a) shows a locative adjunct that does not necessitate special morphology on the verb. Crucially, this is the sentence that would be referred to as a locative GOAL. In contrast, sentence (7b), which requires a locative applicative derivation, has no a locative GOAL meaning. The applicative verb represents means of travel the subject uses to move from one place to another. The meaning of such verbs is equivalent to tambuura 'move in' (by means of).

(7)Ruluuli-Runyala(Bantu, Uganda; Primary source)

(a) A-ku-yab-a ku e-iduuka 3sgS-PROG-go 17.LOC AUG-5.shop

'He is going to the shop.'

(b) A-ku-yab-ir-a mu e-motoka

3sgS-PROG-go-APPL-FV 18.LOC AUG-9.vehicle
'He is going in a vehicle.'

It can further be shown that in Ruluuli-Runyala, the locative GOAL meaning is non-existent even with the verb of tuma 'send'. In sentence (8a) below, a locative prepositional phrase that requires no morphological processes with the verb is given. Incidentally, this is the sentence that would be given a locative GOAL meaning. In comparison with sentence (8b), tumira 'send for' has a beneficiary interpretation. This is the same meaning that is deduced with this verb-synonyms like weereza 'send,' except that the latter takes an applicative 'infix' as in weere-re-za 'send for'.

(8) Ruluuli-Runyala (Bantu, Uganda; Primary source)

(a) Tum-a o-mwana ku e-isomero.

Send-FV AUG-1.child 17.LOC AUG-5.school

'Send a child to school.'

(b) N-tum-ir-a o-mwana ku e-isomero

1sgS-end-APPL-FV AUG-1.child 17.LOCAUG-

5.school

'Send for me a child to school.'

Jerro (2017) describes the locative applied object as PATH. He adopts Asher and Sablayrolles (1995)'s definition of PATH as strict internal path that involves a portion of path which does not include SOURCE or GOAL. Mostly, this involves verbs which, in addition to allowing locative phrases in non-applicative construction, permit locative applicative arguments that show PATH. Jerro mentions Ruluuli-Runyala-verb equivalents like ingira 'enter', wuluka 'exit', niina 'climb', niina 'ascend' and sirimuka 'descend' to fall in this category. This is found true in respect of Ruluuli-Runyala as shown below:

(9) Ruluuli-Runyala (Bantu, Uganda; Primary source)

(a) O-kapa a-ku-wulik-a omu e-kisiika.

AUG-1.cat 3S-PROG-exit-FV 18.LOC AUG7.room

'The cat is exiting the room.'

(b) O-kapa a-ku-wulik-ir-a omue-dirisa e-nnyumba

1.cat 3S-PROG-exit-APPL-FV 18.LOC AUG7.room

AUG.9.house

'The cat is exiting the room through the window.'

Sentence (9a) shows that the verb wuluka 'exit' can carry a locative phrase in a non-applicative construction. The locative PATH meaning is given in sentence (9b) as the locative applicative derivation is employed.

Lastly, there is the locative SOURCE, which depicts the applied object as indicative of a starting-point of the event in motion. Ruluuli-Runyala has evidence of this locative meaning as exemplified below:

(10) Ruluuli-Runyala(Bantu, Uganda; Primary source)

(a) O-musobbi a-somok-ere e-nyanja

AUG-1.expert_sailor 3sgS-cross-PFV AUG-9.lake 
'The expert tailor crossed the lake.'

(b) O-musobbi a-somok-e-ire e Galiraaya e-nyanja

AUG-1.sailor 3sgS-cross-APPL-PFV

17.LOC

$$
\text { 1.Galiraaya AUG-9.lake }
$$

'The expert tailor crossed the lake at Galiraaya.'

Sentence (10a) has no oblique object in the nonapplicative form. However, the introduction of the locative SOURCE argument e Galiraaya 'at Galiraaya' makes the applicative derivation obligatory. The applied object, in this case, is a locative SOURCE meaning.

Jerro (2017:4) suggests the presence of 'unity of verb classes' between languages while differing from Rugemalira (1993), who rejects the notion of semantically defined verb classes, such as motion verbs. The meaning of Jerro's 'unity of verbs classes', however, is also not clear. If it is construed in relation to the four locative meanings in the typology description, it is too inadequate to capture all locative applicative meanings. In RuluuliRunyala, there are locative meanings that are contextual and semantically word-specific such that they do not fall in any of the four typological meanings. We mention some examples below:

(11) Ruluuli-Runyala (Bantu, Uganda; Primary source)

(a) N-ku-biik-a e-sente mu nte 1sgS-PROG-save-FV AUG-9.money 18.LOC1.cow 'I am saving money in cows.'

(b)N-ku-biik-ir-a mu nte e-sente 1sgS-PROG-save-APPL-FV 18.LOC 1.cow AUG9.money

'I am saving money in cows.'

The sentence in (11a) above shows that biika 'save' can be used transitively with a locative phrase in a nonapplicative construction. The locative meaning obtained for sentence (11a) is similar in meaning to sentence (11b), where a locative applicative has been used. The applied object in both cases is not just a place as location but rather a fixed asset, nte 'cows'. Such a verb can select different applied objects, but convey a similar locative interpretation. For example, save money in education, land, fish,children and others. We also give another example of another locative meaning using the verb sooka 'start' in the sentence below:

(12) Ruluuli-Runyala (Bantu, Uganda; Primary source) O-sook-er-a kumaizi

2sgS-start-APPL-FV 17.LOC 6.water

'You start with the water.'/'You start from the water.'

Whereas sentence (12) would correspond to general locative as in where the event took place, it can also have a quite different interpretation. It needs a pragmatic interpretation to analyse sookera as either 'start from' or 'start with'. On the one hand, 'start with' means at the very first stage of an event or process. Therefore, the sentence means one has to first access water before doing anything else after reaching a destination. On the other hand, 'start from' typically conveys a general locative reading. We also give another locative meaning where its general sense is compared with command strategies using the verb kanga 'stop' below:

(13) Ruluuli-Runyala (Bantu, Uganda; Primary source)

(a)kang-a awo!

stop ADV

'Stop there!'

(b) kang-ir-a awo!

stop-APPL-FV ADV

'Stop there!' (stop at that point!)

The example in (13a) illustrates the use of kanga 'stop' as a command to stop movement or progress of an activity. The command can be construed as a locative applicative in (13b) because of the equivalent to the adverbial demonstrative there (Dixon, 2009:247). In RuluuliRunyala, both kanga and kangira are used interchangeably to mean stop at that point. This would reflect a locative applicative meaning in which a general locative sense is reduced to an event bounded with precision or a specific spot.

In Ruluuli-Runyala, there are more instances where Jerro (2017)'s locative typology framework offers a limited interpretation. Evidence shows locative semantics can be much wider and also can depend on underlying metaphors of spatial and abstract location (Marten and Kula, 2014). Instead of a physical location, some events seem to occur in symbolic settings where the context can bring about a unique interpretation as shown in example below:

(14) Ruluuli-Runyala (Bantu, Uganda; Primary source)

(a) E-bintu bi-amwe a-bi-koo-r-a mu nkukutu AUG-8.thing8-3sgPOSS 3sgS-8O-do-APPL-FV 18.LOC 9.secretiveness

'He does his things in secretiveness.' (He does his things from a hideout."

The locative phrase mu nkukutu 'in secretiveness' would literally mean one working from a hiding place which would be construed as general locative. Instead, a workplace is expressed as a hideout which symbolises secretiveness in the way one conducts his/her daily business.

Dixon (2012) recognises that there are many other varieties of locative expressions that may be used as applicative arguments. We have shown that the four typological locative meanings advanced by Jerro (2017) are not exhaustive in respect of the lexical semantics of all verbs. Locative applicative markers in Ruluuli-Runyala 
reflect more complex functions and interpretations of Bantu applicatives. They represent the interaction of abstract applicative and locative semantics in a much broader way than the four typological meaning categories because more underlying metaphors of spatial and abstract locations are not captured. Static location, source of movement and direction of movement that can be coded by either locative affixes or locative prepositions depends entirely on the meanings of individual verbs (Creissels, 2004).

\section{Goal applicative object}

Dixon (2012) defines goal applicative as an activity or state described by the verb of an applicative construction. When a goal applicative applies to verbs, like weerya 'give' koba 'tell' and langa 'show', the subject argument keeps as it is, while the goal argument moves from the peripheral function to the transitive object function. In this situation, the original transitive object in the nonapplicative construction moves into the applicative case (Kimenyi, 1980; Chung, 1986; Dixon, 2009). Some scholars (for example De Kind and Bostoen, 2012; Pacchiarotti, 2017) argue that the primary semantic role of applied objects is GOAL. In essence, all the semantic roles associated with Bantu applicatives like 'beneficiary', 'locative' and others are thought to be secondary. In Ruluuli-Runyala, the applicative marker can licence applicative objects with the GOAL semantic role in different ways. Dixon (2012) gives four ways through which this goal semantic role can be analysed in languages. Below we illustrate the first GOAL meaning sub-category of Additional argument:

$$
\text { Ruluuli-Runyala (Bantu, Uganda; Primary }
$$
source)

$$
\begin{array}{ccc}
\text { (a) A-ku-kuutil-a e-nsonga ya bukuni } \\
\text { 3sgS-PROG-emphasize-FV AUG-9.issue } \\
\text { 14.cleanliness }
\end{array}
$$

'He is emphasising the issue of cleanliness.'

(b) A-kuutil-ir-a a-bantu e-nsonga ya bukuni
3sgS-PROG-emphasize-FV AUG.2.person AUG-

\section{9.issue 9.GEN 14.cleanliness}

'He is emphasising the issue of cleanliness to the people.'

Sentence (15a) indicates a self-contained clause that can stand alone in a non-applicative construction using the transitive verb of kuutila 'emphasise'. To the people is an extra argument indicating GOAL which is then added to the sentence in (15b). The applicative derivation licences the extra argument into the transitive object position of sentence (15b) indicating to who the emphasis was directed. In this position, the applied object shows symmetric object properties, that is, being closer to the subject, being cross-referenced with the verb and being a subject of the passive (Bresnan and Moshi, 1990; NgonyaniandGithinji, 2006). This is also considered as a case of promoting an applied object from a peripheral object function to the transitive object function (Cann andMabugu, 2007; Trithart, 1983).

The second sub-category of semantic GOAL applicatives that can be assigned to applied objects is Recipient. It involves putting the Gift or Recipient in a transitive object function of certain verbs like 'send', 'sell', 'lend' and others in the English language (Dixon, 2012). Under Recipient semantic role, the applied object is not in so close a relation to the entire verb phrase, instead to the theme object. The theme is primarily intended for the applied object which in this case is a Recipient. Not at all times should the action of the verb be beneficial to the applied object. In respect of a sentence "Tanga gave me a slap", the reception can be negative in that context (Cann and Mabugu, 2007:226). There are also possession relations between the applied object and the patient object similar to 'low applicatives' (Pylkkänen, 2008). Otherwise, Recipient in Ruluuli-Runyala occurs with only transitive verb bases, which is not the case with Beneficiary (De Kind andBostoen, 2012). Nevertheless, the two are closely related in a sense that they share the same verb-valency and morpho-syntactic behaviour of their objects. Recipient semantic role in Ruluuli-Runyala can be illustrated below:

(16) Ruluuli-Runyala (Bantu, Uganda; Primary source)

O-zeiza a-ku-twal-ir-a a-baizukulu
baamwee-nsuwa
1.grandpa 3sgS-PROG-take-APPL-FV AUG-
2.grandchild 3sgPOSS AUG-pot
'Grandfather is taking the pot to his
grandchildren'.

According to sentence (16), Ruluuli-Runyala restricts having a Gift as a transitive object in a Recipient-driven applicative construction. It is not possible to put the Gift ensuwa 'pot' in the transitive object slot of abaizikulu 'grandchildren'. The two cannot be interchangeably used as is the case in English. In English, one can only say/ took Joan a pot; but not *I took a pot Joan. Otherwise, in order to have the direct object precede the indirect object, one must use a prepositional phrase construction I took a pot to Joan (Isingoma, 2018). At the same time, the Recipient cannot be used as an oblique object in RuluuliRunyala (Kitillä, 2005; Dixon, 2012; Marten and Kula, 2014).

Applicative verbs can be used as 'stimulus' for a stative verb which in this case would be another subcategory of Goal applicatives. This involves the derivational applicative process in the use 'stimulus' or motivating factor for stative verbs. Dixon (2012:326) explained that 'human propensity adjectives' like 'happy (about)' or 'ashamed (of)' in English are exclusively used with or 
without a prepositional phrase stating the stimulus.

In Ruluuli-Runyala, such notions are expressed through stativeverbs. The sentence takes an intransitive construction with a peripheral argument showing the 'stimulus'. Such a sentence can also be realized in a transitive applicative construction (Onishi, 2000). Goalstimulus for a stative verb applicative construction involves expressions such as sanyuka'get happy' and camuka 'get excited' as illustrated in example (17) below:

$$
\text { Ruluuli-Runyala }
$$

(Bantu, Uganda; Primary source)

(a)N-a-sanyuk-a okulwa a-bageni

2.visitor 1sgS-FUT-get_happy-FV PREP AUG-

'1 will get happy for the visitors.'

(b) N-a-sanyuk-ir-a a-bageni 1sgS-FUT-get_happy-APPL-FV AUG-

2.visitor

"I will get happy for the visitors."

In sentence (17a) abageni 'visitors' is in the peripheral function enabled by the preposition okulwa 'for' in an intransitive construction. In sentence (17b), the applicative marker licences the formerly peripheral argument to assume a transitive object function. The 'stative' verb camuka 'get excited' also behaves in the same way as sanyuka 'get happy' in Goal-stimulus applicative marking. Such verbs can also take double applicative construction when the derived verb is used with an adverbial kakyarumwei 'very' as shown below:

(17) Ruluuli-Runyala (Bantu, Uganda; Primary source)

(a) N-a-camuk-ir-a kakyarumwei

1sgS-FUT-get_excited-APPL-FV ADV

'I will get very excited.'

(b) N-a-camuk-i-ir-a

1sgS-FUT-get_excited-APPL-APPL-FV

'I will get very excited.'

The applicative construction in sentence (17a) uses the adverbial kakyarumwei 'very' that is semantically equivalent to the use of double applicative construction in (17b). The derived form in (17b) neither permits a transitive object nor an adverbial kakyarumwei 'very' nor yet strengthens the notion of degree embedded in the semantic meaning of 'very'. This is also an example of non-valency changing applicative construction (Smits, 2017; Kawasha, 2003).

Goal applicatives can also be analysed in respect of 'Stimulus for a corporeal verb' of laughing and crying. In Ruluuli-Runyala, corporeal activities of sobbing, weeping, crying, smiling, and laughing can all have their 'stimulus' expressed by means of the applicative marker. In other words, the applicative is obligatory to show what is being, say, cried over or smiled at or wept for. This is illustrated in the sentences below:
(18) Ruluuli-Runyala

(Bantu, Uganda; Primary source)

(a) Lwaki o-ku-sek-e-er-a kateica

INTERR 2sgS-PROG-laugh-APPL-APPL-FV 1.poor_person

'Why are you laughing at the poor person?

(b) Lwaki o-ku-kung-ir-a o-mutemu

INTERR 2sgS-PROG-weep-APPL-FV AUG-

1.murderer

'Why are you weeping for the murderer?'

The corporeal stimulus argument kateica 'poor person' takes double applicative construction insek-e-er-a 'laugh at' as shown in sentence (18a). In sentence (18b), the 'stimulus' argument omutemu 'murderer' takes single applicative construction in kung-ir-a 'weep for'. The same structure is realised when semantically related verbs to those in question are used. For instance, the 'corporeal stimulus' argument can take the derived verb mweny-eer-a 'smile gently' from mwenya 'smile' while bbok-er-a 'cry out for' can be the derived verb from bboka 'cry out'.

\section{Instrumental applicative object}

Dixon (2009:446) analyses an instrument as case inflection marking in which "the referent of the NP is attached as a weapon, tool, or material used in the action of the verb." By this interpretation, applicative arguments can refer to actual or notional instruments (Dixon, 2012).

Dixon (2012) put forward five subcategories of Instrumental applicative objects. They include Instrumental cause/Instrumental-reason, Instrumental assist, Instrumental implement, Instrumental material and Instrumental surface effect. Instrumental applicatives in Ruluuli-Runyala can occur through applicative/causative isomorphism (Peterson, 2007). The suffix realisation grammaticalises as a causative marker -esyand -isy, which extends to an instrumental applicative marker. Although all the above mentioned subcategories are found in Ruluuli-Runyala, they occur under different syntactic and semantic realisations as examined below:

\section{Instrumental cause/Instrumental-reason}

(19) Ruluuli-Runyala (Bantu, Uganda; Primary source).

O-mukwenda a-a-fu-er-e-ire omu butandwa

AUG-messenger 3sgS-PST-die-APPL-APPL-PFV

PREP 14.accident

'The messenger died in an accident.'

(20) Ruluuli-Runyala (Bantu, Uganda; Primary source) 


\author{
A-a-ki-many-i-ire \\ $\mathrm{mu}$ \\ e- \\ mpapula_z'amawuuro \\ 3sgS-PST-know-APPL-PFV \\ 10.newspaper \\ 'He knew it from newspapers.' \\ PREPAUG-
}

The applicative argument butandwa 'accident' in the complement of sentence (19) indicates the 'cause of death'. Similarly, empapulaz'amawuuro 'newspaper' is the applicative argument indicating 'the means by which one knew' something in sentence (20). The notional instruments showing cause and means in both cases are linked to the main clause in a derivational applicative behaviour. Another example of Instrumental-reason, this time, involving 'because of' is found in Yamukubb-i-ire mwenge ' $\mathrm{He}$ beat her because of alcohol'.In such examples, the instrument 'often occurs as a prepositional phrase' (Saeed, 2016:176).

\section{Instrumental-assist}

(21) Ruluuli-Runyala (Bantu, Uganda; Primary source) $\begin{array}{ll}\text { Omutegi a-yab-ir-ire mu } & \text { e-ryato } \\ \text { 3sgS-PST-go-APPL-PFV } & \text { PREP AUG- }\end{array}$

9.boat

'The fisherman went by boat.'

In sentence (21) above, the applicative argument is eryato 'boat', which plays the role of something that assists the event/activity described by the verb in question. The 'boat' is the actual instrument that assisted the referent of the subject NP, 'the fisherman' to go from one area to another. This is the only case of Instrumentassist provided by the available data that can be realised through the applicative derivation. Other possible constructions as mentioned by Dixon (2012) can only be possible through applicative/causative isomorphism (Peterson, 2007).

(22) Ruluuli-Runyala (Bantu, Uganda; Primary source)

(a) Teg-esy-a a-katimba.

Fish-CAUS-FV AUG-12.net

'Fish with net',

(b) Bumb-isy-a e-ibumba. Mould-CAUS-FV AUG-5.clay

'Mould with clay.'

(c) Bbw-esy-a o-muguwa.

Tie-CAUS-FV AUG-3.rope

'Tie with a rope.'

In respect of examples (22a) and (22b) above, instruments akatimba 'net' and eibumba'clay' assume the transitive object function due to the causative suffix isy. The causative suffix -esy is used in sentence (22c) with the instrument omuguwa 'rope' in a transitive object function. Despite showing features of causative semantics, such instrumental arguments are called instrumental applicatives because they display applicative morphology behaviours (Bostoen and Mundeke, 2011; Pacchiarotti, 2017).

\section{Instrumental implement}

In contrast with Instrumental-assist, the applicative argument can be a weapon, tool or implement that physically affects the referent of the original object: In this case, it is called Instrumental implement (Dixon, 2012). In Ruluuli-Runyala, the two Instrumental subcategories use the same causative suffixes -isy and -esy to depict applicative morphology as illustrated below:

(23) Ruluuli-Runyala (Bantu, Uganda; Primary source)

(a) N-a-yat-isy-a e-ibbale o-lutayo o-lwo

1sgS-FUT-break-CAUS-FV AUG-5.stone AUG-11.gourd 11 -that

'I will break that gourd with a stone.'

(b) N-a-kubb-isy-a

o-mwana
1sgS-FUT-beat-CAUS-FV AUG-3.mingling_stick

o-mugai AUG-1.child

'I will beat the child with a mingling_stick.'

(c) Soroor-esy-a e-kikandulyo

Gather-CAUS-FV AUG-garden_fork AUG-

8.grass

'Gather the grass with a garden fork.'

On the one hand, eibbale 'stone' in sentence (23a) and omugai 'mingling-stick in sentence (23b) are instrumental implement arguments licensed by the causative suffix isy. On the other hand, causative suffix -esy licenses ekikandulyo'garden fork' to assume transitive object function. Significantly, the applicative not the causative meaning is manifest in the three derived verbs yat-isy-a 'break with' kubb-isy-a 'beat with'andsoroor-esy-a 'gather with'. All these applied verbsare transitive and valencyincreasing (Bostoen andNzang-Bie, 2010).

\section{Instrumental surface effect and comitative}

According to Dixon (2012), instrumental surface arguments inflict effect on the surface area of the referent of the original object. The effect is so superficial that the instrument does not impact the material nature of the original object. Dixon gives expressions like 'sweep with a broom', 'sprinkle with water', and 'touch with the foot'. In Ruluuli-Runyala, propositions with similar contexts are expressed through double applicative construction, a comitative or a causative that has an applicative reading 
as shown below:

(24) source)

\section{Ruluuli-Runyala}
(a) Yey-a e-kisiik-a ki-amuna o-lweyo Sweep-FV AUG-7.room 7-2sgPOSS
COM AUG-11.broom
'Sweep your room with a broom.'

(b) Yey-esy-a o-Iweyo e-kisiika ki-amu

Sweep-FV AUG-11.broom

7-2sgPOSS

'Sweep your room with a broom.'

AUG-7.room

The Instrument surface argument olweyo 'broom' can be expressed in a peripheral function with the help of comitativena 'with' as shown in sentence (24a). Alternatively, it can be used in a transitive object function with the help of the causative suffix -esyas given in sentence (24b). The use of Instrument surface argument in (b) is once again typical of causative suffixes which show applicative morphology.There is no typical comitative applicative marker in Ruluuli-Runyala. There occurs the same applicative/causative isomorphism as in Instrumental applicatives (Peterson, 2007; Shibatani, 2002). The suffix realisation grammaticalises as causative markers -esyand -isy, which extend to a comitative applicative reading as seen in sentences (24a) and (24b) above. The Instrument surface can also be realised through double applicative construction in respect of the verb suka 'sprinkle'. The double applicative brings about the lexicalised derived verb sukiira 'sprinkle with water' as illustrated below:

\section{Ruluuli-Runyala}

(Bantu, Uganda; Primary source)

(a) suk-a omu ngalo za bageni a-maizi sprinkle 18.LOC 9.hand 9.GEN 2.visitor AUG-6.water

'Sprinkle the visitors' hands with water.'
(b) suk-i-ir-a
a-bageni
a-maizi omu
ngalo

Pour_a little at a time-APPL-APPL-FV AUG-2.visitor AUG-6.water LOC 9.hand hands.'1

'Pour water a little at a time on to the visitor's

The Instrument surface argument amaizi 'water' can be in a direct object function in sentence (25a) in the nonapplicative construction. The addition of double suffixes in suk-i-ir-a 'sprinkle with water' allows text restructuring such that the applicative argument can occupy the transitive object slot in sentence (25b). This is an example of applicative verb forms that specify the semantic role of the object they license basically called

\footnotetext{
${ }^{1}$ Contextually, such a sentence is common when 'water' is for washing hands especially when one is going to eat.
}

semantically specified applicative use (Creissels, 2004). Sukiira 'sprinkle with water' is exclusively used to promote the instrumental surface adjunct of amaizi 'water', and contextually, 'water' for washing hands especially when one is going to eat. Another related example of semantically specialised applicative use with respect to Instrumental surface applicatives involves the verb kwata 'hold'. Once the double applicative construction takes effect, the derived verb becomes kwatiira 'hold with hands'

\section{Instrumental material}

Instrumental applicative material codes materials used in an activity. In Ruluuli-Runyala, materials used in activities are also coded as causatives with an applicative reading. Examples of instrumental material applicatives include: kol-esy-andagalaolwomero 'make food-wrappers with banana leaves', serek-esy-aobufumboennyumba 'roof the house with spear grass', mant-isy-a ebinyangataemwomo 'plaster the wall with mud' and sitir-isy-a embigo 'fence with reeds'.

\section{Possessum applicative object}

In Ruluuli-Runyala, there are instances where a possessum can function as an applicative argument. We consider the examples below:

(26) Ruluuli-Runyala (Bantu, Uganda; Primary source)

(a) O-musomesya a-a-kubb-ire a-baana ba-ange

AUG-2.teacher 3sgS-PST-PFV AUG-2.child $3 p l-1$ sgPOSS

'The teacher has beaten my children.'

(b) O-musomesya a-a-n-kubb-i-ire a-baana

AUG-1.teacher 3sgS-PST-1sgO-beat-APPL-PFV AUG2.child

'The teacher has beaten my children.'

The possessum argument in sentences (26a) abaanabaange 'my children' becomes the applicative argument in sentence (26b). Interestingly, the possessive determiner baange $3 \mathrm{pl}-1 \mathrm{sgPOSS}$ is no longer necessary in sentence (26b) because of the applicative construction. However, in instances of a noun possessive case like onkokoyaomwana 'the child's hen' in sentence (27a) below, it is the genetiveya that can be dropped in the applicative construction as shown. source)
(a) O-Musiita a-a-it-ir-ire
o-nkoko
ya 
AUG-1.Musiita3sgS-PST-kill-APPL-PFVAUG-1.hen

1.GEN AUG-1.child

'OMusiita killed the girl's hen.'

(b) O-Musiitaa-a-it-ir-ire o-mwana o-nkoko

AUG-1.Musiita3sgS-PST-kill-APPL-PFVAUG-child AUG-1.hen

'OMusiita killed the child's hen.' (or 'OMusiita killed a hen a for the child' (two meanings)

The applicative constructions in both sentences $(26 \mathrm{~b}$ and $27 b)$ involve pragmatic interpretation. They can imply possessum argument as shown in these very examples, or they can take a benefactive interpretation. That is, sentence (26b) would also imply 'The teacher has beaten the children on my behalf'. Sentence (27b) would also imply 'OMusiita killed the hen on behalf of the child'. A similar case is found in the Bantu language of Chichewa (Simango, 2007).

\section{Temporal applicative object}

In Ruluuli-Runyala, the applicative object can be assigned as temporal. Temporal location is one of the four localist semantic temporal fields. In this case, the event function is used to describe 'Go temporal' that refers to movement in time (Saeed, 2016).

(28) Ruluuli-Runyala(Bantu, Uganda; Primary source)

(a) Ki-a-twal-a-nga o-bwire

7S-PST-take-FV-HAB AUG-14.time

'It would take time.'

(b) ki-a-mu-twal-ir-a-ngao-bwire

7S-PST-3sgO-take-APPL-FV-HAB

'It would take him time.'

AUG-7.time

Sentence (28a) shows a non-applicative construction involving the use of a transitive verbtwala 'take' with an obligatory temporal adverb obwire 'time'. The addition of the applicative argument mu 'him' cannot be complete without the addition the temporal adverbial obwire 'time' describing location in time. Sentence $28 \mathrm{~b}$ shows that the applicative construction can assign the participant the duration of the event functions of twala 'take' (Natumanya, 2012).

\section{Patient applicative object}

A 'patient' refers to entities acted upon and changed by the verb's action. We adopt Saeed's (2016) view that differentiates a patient from a 'theme' although some scholars (Radford and Anderson, 1988; Peterson, 2007; Creissels, 2010) use the two terms interchangeably. In more specific terms, a patient is "the entity undergoing the effect of an action, often undergoing change of state"
(Saeed, 2016: 472). For a theme, it is an "entity moved in literal or figurative space by action of the verb but constitutionally unchanged" (Saeed, 2016: 174). It is the entity which is moved by an action or whose location is described. In Ruluuli-Runyala, patient applicative object can be illustrated in the sentence below:

(29) Ruluuli-Runyala (Bantu, Uganda; Primary source)

(a) A-bombokiba-ku-kon-a e-misumaali

AUG-2.builder 3pIS-PROG-hit-APPL-APPL-FV AUG-

4.nail

'The builders are hitting the nails.'

(b) A-bomboki ba-ku-kon-e-er-a e-misumaali

omu e-misaale

AUG-2.builder 3pIS-PROG-hit-APPL-APPL-FV AUG-

4.nail 18.LOC AUG-4.tree

'The builders are hitting the nails into the trees.'

In sentence (29a), emisumaali 'nails' is a patient object with its transitive meaning achieved in a non-applicative construction. The double applicative construction in sentence (29b) extends the meaning of the patient object to require another complement; for instance, omumisaale 'into the trees'. In the process, the patient changes by the action of the verb since force exerted on the nails may change their shape and size. This is brought about by the repetitiveness of hitting of the nails into trees by the builders. The hitting of nails may be into something like reeds, walls, ceiling and others with the intention to have the nails enter or with the intention of making them compact: The same semantic notion is depicted in koneeraeitakali which means 'hit the soil repeatedly so that it becomes compact'.

\section{Lexicalised uses of applicative objects}

Ruluuli-Runyala also has language particular peripheral marking on applicative arguments involving 'due to the presence of'. This is found in double applicative construction of the derived verb tiiniira 'for fear of' as exemplified below:

(30) Ruluuli-Runyala (Bantu, Uganda; Primary source)

(a) N-ku-tiin-a okulwa a-basirikale

1sgS-INF-be_afraid-FV PREP AUG-2.soldier

'I am afraid due to the presence of the soldiers.'

(b) N-ku-tiin-i-ir-a a-basirikale

1sgS-INF-be_afraid-APPL-APPL-FV AUG-2.soldier

'I am afraid due to the presence of the soldiers.'

The verb tiina'fear/be afraid of' can take an aversive stimulus as its peripheral NP in an intransitive construction as shown in sentence (30a). Being afraid of the soldiers can be expressed in a transitive applicative 
construction with the help of double applicatives-i-iras shown in sentence (30b).

In other specialised language particular periphery marking cases, Ruluuli-Runyala shows a quasiapplicative construction that informs the formation of lexicalised phrasal verbs. We give an example of the monosyllabic verb zwa 'come', which can be used with a participant pronoun awo, which has a semantic equivalence to 'nothing' in such sentences as below:

\section{Ruluuli-Runyala}

(Bantu, Uganda; Primary source)

(a) Ndowo e-ki-zw-ire-mu

PRON 7.REL-7-come-PFV-ECL

'Nothing came out of it.'

(b) N-zw-e-re-ire-mu awo

1sgS-come-APPL-APPL-PFV PRON

'Nothing came out of it for me.' (I have gained nothing from it).

In sentence (31a), there is no an underlying participant to whose benefit or detriment the event of the verb describes. In sentence (33b), the use of double applicatives licenses the introduction of the participant $n$ ' $1 \mathrm{sg}$ ' and an obligatory case that is used as a sentence adverbial following the derived verb. The word awo is semantically equivalent to bwereere 'nothing' in this context. Therefore, one can as well say Nzwereiremubwereere 'I have gained nothing from it'.

Applicative constructions in Ruluuli-Runyala can be used to advance politeness strategies through an implied purpose clause. The derived verb can specifically be meant to offer compliment in instances where the speaker appreciates the addressee's dress code, smartness, appearance, walking style, way of speaking and others. we mention the example below:

\section{(32) Ruluuli-Runyala (Bantu, Uganda; Primary source) \\ O-n-zwal-i-ire o-lugoye! \\ 2sgS-1sgO-wear-APPL-PFVAUG-11.cloth \\ 'You are so well dressed that I admire you.'}

The applicative sentence (32) can be interpreted as an expression of compliment for one is in admiration of the addresee's impressive dressing appearance. The purpose clause 'so that I admire you' is implied by the inclusion of the applicative object $n 1 \mathrm{sg}$. The meaning of the applicative is not tied to the semantic role of the applicative object but rather to the speaker-addressee relationship.

\section{Conclusion}

In respect of the semantic roles of applicative objects analysed in this paper, Ruluuli-Runyala has various semantic role features with both specialised and nonspecialised applicative use. Similar to other Bantu languages like Kichaga (Bantu, Tanzania) the form of the morphological indicator does not change with the semantic role of the applied object (Peterson, 2007).

We argued that Jerro (2017)'s four locative meanings (Locative, Path, Goal and Source) that may be construed from applicative verbs are not exhaustive enough. We illustrated certain cases of verb meanings in objects that can be assigned the semantic role of locative, but seem language-specific and carry unique pragmatic interpretations. We mentioned instances involving verbs like biika "save', sooka 'start' and pragmatic interpretations required in kanga/kangira 'stop at that point' in command strategies. We then argued against Jerro's use of locative prefixes $k u$ and $m u$ as class markers. Instead, we considered them as prepositions in instances of locative adjuncts that do not necessitate special morphology on the verb (Pacchiarotti, 2017).We also concurred with Creissels (2004) in a way that static location, source of movement and direction of movement can be coded by either locative affixes or locative prepositions depending entirely on meanings of individual verbs. Recipient in Ruluuli-Runyala is used with only transitive verb bases, which is not the case with Beneficiary (De Kind andBostoen, 2012). However, the verb-valency and morpho-syntactic behaviour of their objects makes the two similar. In spite of showing features of causative semantics, we refer to instrumental arguments as Instrumental applicatives because they show applicative morphology behaviour (Bostoena nd Mundeke, 2011; Pacchiarotti, 2017). We found no typical comitative applicative marker in Ruluuli-Runyala. Instead applicative/causative isomorphism behaviour similar to Instrumental applicatives takes place (Peterson, 2007; Shibatani, 2002).Although Ruluuli-Runyala is to a larger extent semantically unspecified in assigning semantic roles to applicative arguments as in most Bantu languages, it has examples of semantically specified applicative use (Creissels, 2004). This was shown in Instrumental surface applicatives involving the verb kwata 'hold' and suka 'sprinkle'.

\section{CONFLICT OF INTERESTS}

The author has not declared any conflict of interests.

\section{REFERENCES}

Asher N, Sablayrolles P (1995). A typology and discourse semantics for motion verbs and spatial PPs in French. Journal of Semantics 12(2):163-209.

Beck D (2009). A taxonomy and typology of Lushootseedvalencyincreasing suffixes. International Journal of American Linguistics 75(4):533-569.

Bostoen K, Mundeke L (2011). The causative/applicative syncretism in Mbuun (Bantu B87, DRC): Semantic split or phonemic merger? Journal of African languages and linguistics 32(2):179-218. 
Bostoen K, Nzang-Bie Y (2010). On how "middle" plus "associative/reciprocal" became "passive" in the Bantu A70 languages. Degruyter. pp. 1255-1307. Available at: https://www.degruyter.com/view/journals/ling/48/6/article-p1255.xml

Bowern C (2015). Linguistic fieldwork: A practical guide. New York: Springer.

Bresnan J, Moshi L (1990). Object asymmetries in comparative Bantu syntax. Linguistic Inquiry 21(2):147-185.

Cann R, Mabugu P (2007). Constructional polysemy: The applicative construction in chiShona. Rakova M, Pethő G, Rákosi CS (szerk.) The Cognitive Basis of Polysemy. New Sources of Evidence for Theories of Word Meaning. Frankfurt am Main: Peter Langpp, pp. 221-245.

Chung S (1986). 6 An Object-Creating Rule in Bahasa Indonesia. Studies in Relational Grammar 1(1):219.

Creissels D (2004). Non-canonical applicatives and focalization in Tswana. In symposium Syntax of the World's Languages, Leipzig.

Creissels D (2010). Benefactive applicative periphrases: Editorial Board.University of

Lyon. https://books.google.com.ng/books?hl=en\&lr=\&id=B8tzvbjuRfwC\&oi= fnd\&pg=PA29\&dq=Creissels+D+(2010).+Benefactive+applicative+per iphrases:+Editorial+Board.\&ots=yxAL2I2Y8I\&sig=ka6slswVrml1AR0J 4AAbtjPBNJE\&redir_esc $=y \# v=$ onepage $\& q \& f=f a l s e$

Davis AR (2011). Thematic roles. In: C. Maienborn, K. von Heusinger and P. Portner, eds. Semantics. An international handbook of natural language meaning. Berlin: de Gruyter 1:399-419.

De Kind J, Bostoen K (2012). The applicative in ciLubà grammar and discourse: A semantic goal analysis. Southern African Linguistics and Applied Language Studies 30(1):101-124.

Dixon RM (2009). Basic Linguistic Theory. New York: Oxford University Press Incorporated.

Dixon RM (2012). Basic Linguistic Theory. New York: Oxford University Press Incorporated.

Eberhard DM, Simon GF, Fennig CD (eds.). (2019). Ethnologue: Languages of the World. Twenty-second edition. Dallas: Texas: SIL International.online version.

Givón T (1990). A functional-typological Introduction, II. Amsterdam: John Benjamins.

Hurford JR, HeasleyB, Smith MB (2007). Semantics: A course book. Cambridge: Cambridge University Press.

Isingoma B (2018). Accounting for Variability in the Linearization of Ditransitive Constructions in English among Native Speakers. Argumentum 14:383-399.

Jerro K (2017). The locative applicative and the semantics of verb class in Kinyarwanda. Diversity in African Languages, 289p.

KawashaBK (2003). Lunda grammar: a morphosyntactic and semantic analysis. Ann Arbor: UMI.

Kimenyi A (1980). A relational grammar of Kinyarwanda (Volume 91): University of California Press.

Kimenyi A (1995). Kinyarwanda applicatives revisited. In: 8th NigerCongo syntax and semantics workshop on the applicative architectures. Boston University.

Kitillä S (2005). Recipient-prominence vs Beneficiary-prominence. Linguistic Typology 9:269-297.

Knyazev M (2018). Review of the book: Reinhart T (auth.), Everaert M, Marelj, M, Reuland E (eds.). Concepts, syntax and their interface: The Theta system. Cambridge (MA): MIT Press, 2016.

Maho JF (2009). NUGL Online: The online version of the New Updated Guthrie List, a referential classification of the Bantu languages. Online file: http://goto.glocalnet. net/mahopapers/nuglonline.pdf.

Marten L, Mous M (2015). Valency and Expectation: Bantu Applicatives World Congress of African Linguistics, University of Kyoto, pp. 21-25.

Marten L, Kula NC (2014). Benefactive and substitutive applicatives in Bemba.Journal of African Languages and Linguistics 35(1):1-44.

Nakayiza J (2013). The sociolinguistics of multilingualism in Uganda: A case study of the official and non-official language policy, planning and management of Luruuri-Lunyara and Luganda (Doctoral dissertation, School of Oriental and African Studies, University of London).
Natumanya M (2012). Morpho-Phonological and Syntactic Patterns of Runyankore-Rukiga Applicative Constructions (Master's dissertation, Norwegian University of Science and Technology Trondheim, Norway).

Ngoboka JP (2005). A syntactic analysis of Kinyarwanda applicatives (Doctoral dissertation, University of KwaZulu-Natal). Available at: http://citeseerx.ist.psu.edu/viewdoc/download?doi=10.1.1.896.9317\& ep=rep1\&type=pdf

Ngonyani D, Githinji P (2006). The asymmetric nature of Bantu applicative constructions. Lingua 116(1):31-63.

Onishi M (2000). Transitivity and valency-changing derivations in Motuna. Changing valency: Case studies in transitivity,pp.115-143.

Pacchiarotti S (2017). Bantu applicative construction types involving*-id: form, functions and diachrony. (Doctoral dissertation, University of Oregon).

Peterson DA (2007). Applicative constructions: Oxford University Press.

Pylkkänen L (2008). Introducing arguments, MIT press. Volume 49.

Radford A, Anderson SR (1988). Transformational grammar: A first course. Cambridge University Press. Volume 1.

Reimer N (2010). Introducing Semantics. New York: Cambridge University Press.

Reimer N (2016). Routlegde Handbook of Semantics. New York: Routledge.

Rugemalira J (1993). Runyambo verb extensions and constructions on predicate structure.(Doctoral Dissertation, University of Califonia Berkeley).

Saeed JI (2016). Semantics. Chichester: John Wiley and Sons.

Schadeberg TC (2003). Derivation. In: Nurse D andPhilippson G (eds.). The Bantu languages (Routledge Language Family series). London: Routledge, pp. 71-89.

Shibatani M (Ed.) (2002). The grammar of causation and interpersonal manipulation. Amsterdam/Philadelphia: John Benjamins Publishing. Volume 48

Simango SR (2007). Enlarged arguments in Bantu: evidence from Chichewa. Lingua 117(6):928-949.

Smits HJ (2017). A grammar of Lumun: a Kordofanian language of Sudan (Doctoral Dissertation, LOT).

Trithart ML (1983). The applied affix and transitivity: a historical study in Bantu (Doctoral dissertation, University of California, Los Angeles).

Valin Van RD (1999). Generalized semantic roles and the syntaxsemantics interface. Empirical issues in Formal Syntax and Semantics 2:373-389.

Van de Velde $M$ (2010). The syntax of verb complements and the loss of the applicative in Eton (A71). Bantu languages: Analyses, Description and Theory pp. 281-294.

Woolford E (2001). Conditions on object agreement in Ruwund (Bantu). Indigenous Languages pp. 177-201. 